\title{
Serviço Social: razão ontológica ou instrumental?
}

\author{
José Fernando Siqueira da Silva
}

Universidade Estadual Paulista Júio de Mesquita Filho (Unesp, Franca)

\section{Serviço Social: razão ontológica ou instrumental?}

Resumo: O presente ensaio analisa a oposição entre as perspectivas ontológica e instrumental, tendo como referência o campo particular das profissões e o processo de formação profissional dos assistentes sociais. Para tanto, remete a uma importante questão: que tipo de profissional pretende-se formar, intelectuais ou técnico-operativos? Além disso, considerando o atual estágio de acumulação do capital, procura contribuir para o debate contemporâneo acerca da direção social estratégica assumida, a partir dos anos 1990, pelas principais organizações representativas da categoria profissional dos assistentes sociais no Brasil.

Palavras-chave: Serviço Social. Ontologia. Práxis.

\section{Social Work: ontological or instrumental reason?}

Abstract: This essay analyzes the opposition between ontological and instrumental perspectives as a reference for the particular field of the professions and the process of professional education of social workers. To do so it raises an important question: what type of professional is to be educated, intellectuals or technical-operatives? Considering the current stage of capitalist accumulation, it seeks to contribute to the contemporary debate about the strategic social direction assumed since the 1990s by the main representative organizations of the professional category of social workers in Brazil.

Keywords: Social Work. Ontology. Praxis. 


\section{Situando o tema}

A gênese do Serviço Social como profissão "socialmente legitimada e legalmente sancionada" (NETTO, 1992, p. 13) está estrutural e decisivamente vinculada a um amplo processo tecido sob as condições do capitalismo de monopólios que se anunciou no final do século 19 e, inicialmente, desenvolveu-se em boa parte do século 20, sob o padrão de acumulação fordista (GRAMSCI, 1989; HARVEY, 2003; ANTUNES, 1999). Nesse cenário, interagiram, como forças subsidiárias, o movimento secular da Igreja Católica, empenhado em retomar mundialmente sua hegemonia em uma sociedade de classes em ascensão, e os estados nacionais organicamente capturados pela fase monopolista da acumulação do capital. Todo chão sócio-histórico foi geneticamente estremecido e potencializado pelos levantes da classe operária na Europa a partir da segunda metade do século 19, consideravelmente tratados por Marx e Engels no conjunto de sua obra e por Lenin (2008), Rosa Luxemburgo (2007), Gramsci (1989) e Lukács, (1978, 1979, 1981). Sendo assim,

[...] na emergência profissional do Serviço Social, não é este que se constitui para criar um dado espaço na rede sócio-ocupacional, mas é a existência deste espaço que leva à constituição profissional [...] não é a continuidade evolutiva das protoformas ao Serviço Social que esclarece a sua profissionalização, e sim a ruptura com elas [...]. A profissionalização do Serviço Social não se relaciona decisivamente à 'evolução da ajuda', à 'racionalização da filantropia' nem à 'organização da caridade'; vincula-se à dinâmica da ordem monopólica (NETTO, 1992, p. 69, grifos do autor).

Esse legado conservador, originalmente embebido em uma concepção doutrinária e reparadora da ordem (IAMAMOTO; CARVALHO, 1985), bem como gradativamente inspirado em fragmentos de diferentes concepções teóricas, extraídas das Ciências Humanas e Sociais, foi objeto de uma primeira e importante revisão que se expressou no chamado processo de reconceituação, movimento latino-americano que durou cerca de dez anos, estendendo-se da segunda metade dos anos 1960 à primeira metade dos anos 1970. Vale destacar que todo esse processo foi marcado pela autocracia burguesa na América Latina (NETTO, 1992), certamente em tempos diferentes; autocracia objetivada por meio da imposição de governos ditatoriais que passaram a gerenciar a máquina do Estado burguês com "mãos de ferro".

O importante processo de reconceituação mostrou-se, ao mesmo tempo, relevante e limitado, ou seja, foi espaço de debate, sistematização e esforço teórico-metodológico para além do Serviço Social tradicional (NETTO, 1992), porém reprodutor de inúmeros problemas que repuseram, por meio de diferentes inspirações teóricas (NETTO, 1991), a base sincrética do Serviço Social. Essa reposição teve requintes de ecletismo que se moveu por linhas teórico-metodológicas antagônicas, no geral, pouco ou insuficientemente afeitas à leitura das obras clássicas originais, frequentemente tomadas por meio de manuais ou de interpretações pontuais elaboradas, sobretudo, a partir do positivismo-funcionalismo, da fenomenologia e dos marxismos ${ }^{1}$.

A partir dos anos 1990, foi possível realizar um balanço mais rigoroso do legado deixado pelo Serviço Social brasileiro. Um maior amadurecimento no âmbito da produção do conhecimento foi acompanhado por intervenções decisivas no campo da formação profissional, na revisão crítica do Código de Ética (1993), no fortalecimento das organizações de defesa da categoria profissional de forma mais articulada, expressas no Conselho Federal de Serviço Social (Cfess), nos Conselhos Estaduais (Cress) e na Associação Brasileira de Ensino e Pesquisa em Serviço Social (Abepss), entidades que foram potencializadas por forças progressistas e por meio de lutas concretas que contribuíram para uma revisão do entulho autoritário deixado pelos mais de 20 anos de regime ditatorial. Todavia, esse processo de redemocratização política no Brasil, longe de expressar o abrandamento da autocracia burguesa, recolocou sua hegemonia sob o "manto sagrado" da democracia cidadã que parecia ser o grande remédio para os males do país em tempos de crise do socialismo real e do "fim da história". Simultaneamente, uma nova fase do capitalismo de monopólios se inaugurou concretamente em território nacional (já em curso na Europa desde a segunda metade dos anos 1970), momento esse inspirado no ultraliberalismo, na composição de estados nacionais cada vez mais fortalecedores do capital e facilitadores da apropriação privada de fundos públicos, no padrão de acumulação toyotista, na flexibilização das relações de trabalho, na desoneração do processo produtivo, e na potencialização - no sentido marxiano - do capital constante destinado à intensificação tecnológica em detrimento do capital variável que compõe a remuneração da força de trabalho. Essa alteração na composição orgânica do capital (MARX, 1984) feriu profundamente a organização da classe trabalhadora, eliminou postos de trabalho, destruiu direitos sociais e trabalhistas, criou uma massa de subempregados, de trabalhadores informais e desempregados permanentes, precarizou as relações formais de trabalho, quebrou o poder dos sindicatos e fortaleceu o capital diante do trabalho (ANTUNES, 1999, 2000; HARVEY, 2003)22.

Ora, esse contexto, inegavelmente, atingiu o Serviço Social, impôs concretamente limites e desafios para essa profissão nos campos da formação e do trabalho profissional, alterou a composição das políticas 
sociais, redimensionou o perfil do principal empregador dos assistentes sociais (o Estado), precarizou a vida desse profissional como trabalhador, aligeirou sua formação intelectual e desumanizou os usuários atendidos pelo Serviço Social. Em outras palavras, teve um impacto nas dimensões teórico-metodológica, ético-política e técnico-instrumental do assistente social na medida em que reconfigurou seu espaço ocupacional, fragmentou suas ações, precarizou e focalizou programas e projetos sociais, aspectos enriquecidos pelo atual estágio de acumulação do capital sob as condições hipertardias da revolução burguesa brasileira e de sua via colonial (FERNANDES, 1987).

O que se pretende, a seguir, no campo particular do Serviço Social, é analisar a pertinência de se investir em uma formação profissional inspirada no ponto de vista ontológico, diferenciando-a de qualquer tradição que reduza o processo formativo a uma racionalidade essencialmente instrumental. Para tanto, dois aspectos são particularmente importantes: a) o reconhecimento da dificuldade em se propor uma aproximação entre uma profissão cuja gênese esteve atrelada ao pensamento conservador e à reforma social no capitalismo, e uma teoria social crítica ao capital comprometida com sua superação real; b) a afirmação do ponto de vista ontológico no Serviço Social, indicando caminhos concretos a serem percorridos para endossar essa perspectiva como orientação geral.

\section{A teoria social de Marx e a ontologia do ser social}

Não é preciso um grande esforço para argumentar que o cenário em curso não estimula o tratamento do real, sob o ponto de vista da totalidade, para além de sua imediaticidade, como "concreto pensado", como unidade contraditória que se compõe em um processo material-intelectual, marcado por um legado histórico que atravessa a particularidade do Serviço Social e por tensões presentes na historicidade que desafiam concretamente a produção do conhecimento sobre o ponto de vista ontológico. O funcionamento da ordem burguesa madura reafirma, cotidianamente, o tratamento imediato, fenomênico do real ao invés de estimular seu desvelamento. Esse procedimento envolve simples ações cotidianas na relação direta com o consumo de mercadorias objetivadas pelo trabalho humano-abstrato (MARX, 1983) ${ }^{3}$, até iniciativas aparentemente mais complexas, ditas "acadêmicas", marcadas pelo "rigor teórico", orientadas pela ciência burguesa de cunho meramente instrumental, descritivo e sem o menor compromisso com a necessária mediaticidade da vida social.

O ponto de vista ontológico exige uma relação orgânica com a realidade no processo de produção de conhecimento. Seu ponto de partida (apenas ponto de partida) é a realidade que incita, provoca, impõe desafios, indaga, levanta dúvidas, expressa contradições que, todavia, somente são desveladas com o apoio da razão crítica que se debruça sobre o mundo concreto. A dinâmica do real não se revela por si mesmo; carece de uma dimensão racional-intelectual que mira a realidade e reconstrói suas determinações, suas categorias e mediações constitutivas (ainda que sempre relativamente, não exatamente). O conhecimento pautado na ontologia do ser social, historicamente determinado, na sua existência real-concreta, reconhece um movimento material que se situa para além das mentes pensantes, da abstração filosófica orientada pela subjetividade do ser ou por um conjunto de regras cientificamente manipuladas pelo rigor do pesquisador, uma vez que persegue o movimento do real, a racionalidade nele contida. Todavia, essa reconstrução não é espontânea, não brota naturalmente dessa realidade. Carece, portanto, da razão pensante potencializada por sujeitos históricos possíveis, relativos, que se apropriam desse movimento material com o objetivo de desvelá-lo. Todo esse processo não prescinde de outras duas categorias importantes: o legado histórico e o momento histórico, a historicidade. Sendo assim, estamos diante de outra relação entre sujeito e objeto, entre razão e realidade, explicada na sua unidade-diversa, uma produção de conhecimento que parte de demandas reais, imediatamente postas, e as transcendem reconstruindo múltiplas medições extraídas da própria dinâmica do real. O ponto de partida é a realidade que também deve ser o ponto de chegada com o objetivo de transformá-la por meio de alternativas reais, efetivas, materiais, concebidas a partir de possibilidades inscritas na vida real dos homens, sem abstrações. Nega-se, então, a impossibilidade de uma razão objetiva, incapaz de perseguir a "lógica da coisa" (MARX, 2005), como razão meramente subjetiva e fenomenal (aos moldes de Kant), bem como a razão absoluta hegeliana, o espírito absoluto dialético, que se impõe diante da vida material, manipula seu movimento, funda sua lógica (como "coisa da lógica"), estabelece seus parâmetros materiais. Supera, ao mesmo tempo, as diferentes formas restritas de materialismo, que recaem na abstração, inclusive na sua forma mais sofisticada: o materialismo contemplativo e sensível de Feuerbach.

O concreto é concreto, porque é a concentração de muitas determinações, isto é, unidade do diverso. Por isso, o concreto aparece no pensamento como o processo de concentração, como resultado, não como ponto de partida e, portanto, o ponto de partida também da intuição e da representação. No primeiro caminho a representação plena volatiliza-se na determinação abstrata; no segundo, as determinações abs- 
tratas conduzem à reprodução do concreto por meio do pensamento. 'Assim é que Hegel chegou à ilusão de conceber o real como resultado do pensamento que se concentra, que se aprofunda em si mesmo e se apreende a partir de si mesmo como pensamento móvel'; enquanto que o método que consiste em elevar-se do abstrato ao concreto não é senão a maneira de proceder do pensamento para se apropriar do concreto, para reproduzi-lo espiritualmente como coisa concreta [...] (MARX, 1989, p. 410, grifos nossos).

O ponto de vista mais alto a que leva o materialismo 'contemplativo', isto é, o materialismo que não concebe o sensível como atividade prática, é a contemplação dos indivíduos singulares na 'sociedade burguesa'. O ponto de vista do velho materialismo é a sociedade 'burguesa'; o ponto de vista do novo é a sociedade humana, ou a humanidade socializada. Os filósofos apenas 'interpretaram' o mundo de diferentes maneiras; porém, o que importa é 'transformá-lo' (MARX, 2007, p. 539, grifos nossos).

Sendo assim, o ponto de vista da totalidade não se confunde com um todo articulado, sistemicamente interligado, reduzido à comunicação intensa das partes, muito menos se resume a uma visão genérica, estéril, que dissolve as partes no todo. A noção de totalidade traz, em si, a unidade de dimensões diferentes que são impensáveis, inexplicáveis, sem a íntima conexão entre o imediatamente aparente e o processo genético que o explica. O singular, o imediatamente posto, contém o todo na sua riqueza (a universalidade do processo), com suas múltiplas particularidades e mediações, mesmo que não o revele de imediato. Sendo assim, revela-se sempre, imediatamente, ainda que seja rico em determinações. Os indivíduos, seres sociais humano-genéricos, produtos sociais de uma construção histórico-social, são seres que trazem na sua constituição o legado humano, a construção histórica humana, ainda que sob condições particulares. Essa é a trama que compõe a categoria da totalidade como parte de um processo único e indivisível da tríade singular, universal e particular.

Mas isso ainda não é suficiente para explicar a densidade da teoria social ora explicitada. A armadilha está em destacar deste referencial o seu método (como se isto fosse possível), ainda que seja ele o único traço ortodoxo na obra marxiana (LUKÁCS, 1981, p. 59). O ponto de vista da totalidade exige que o método seja apropriado com base em outros dois aspectos inseparáveis entre si: a teoria do valor-trabalho e a perspectiva da ruptura da ordem burguesa em curso (a revolução como possibilidade histórica concreta). Sem isso a teoria social de Marx perde-se por completo. Cabe destacar, sumariamente, a necessidade de considerar essas duas dimensões sem as quais a economia política burguesa não pode ser desvelada e radicalmente questionada a partir de suas contradições internas, ontologicamente dadas e insuperáveis sob o mando do capital. É importante reconstruir permanentemente essa tradição teórica saturando-a com as ricas determinações repostas ao longo dos últimos 150 anos, expressas no movimento histórico marcado por um processo de luta de classes travado no capitalismo maduro. Somente nesse patamar é possível perseguir o movimento do real, sempre relativamente, portanto, nunca exatamente. Lukács destaca a importância de explicar as sociedades e seus indivíduos tendo por base os processos históricos e os complexos sociais que os constituem, considerando o modo como se desenvolvem, produzem-se e reproduzem, ou seja, se organizam economicamente. Isso não significa recair no economicismo que submete mecanicamente toda superestrutura ideológica à base econômica.

[...] uma ontologia do ser social deve, portanto, se não quiser falsear os nexos ontológicos, tentar apreender exatamente seus traços específicos em seu originário ser-propriamente-assim. E para o ser social é profunda e decisivamente característico que todos os processos dinâmicos dos complexos da práxis humana, só nele constituídos e só nele possíveis, sejam quanto à sua gênese fundados no respectivo modo de desenvolvimento da sociedade, em sua economia, e que sejam por ela determinados até as suas características específicas; em sua dinâmica imediata, ao contrário, podem reclamar para si uma muito ampla vida própria, um desdobramento dinâmico próprio, tanto em termos formais como em termos de conteúdo [...]. Um dos motivos principais da vulgarização do marxismo, que tanto colaborou para que ele perdesse sua influência como teoria universal do desenvolvimento da humanidade, foi exatamente a concepção mecanicista de toda ideologia como mero 'produto naturalmente necessário' das respectivas relações econômicas (LUKÁCS, 2010, p. 100/113, grifos do autor).

Ora, sob esse nível, não é possível pensar a teoria destacada do método e da história concreta dos homens, e vice-versa. Mais do que isso, a teoria não é um conglomerado de conhecimentos elaborados abstratamente pelo saber científico, metodicamente organizado, mas sim uma forma específica de conhecimento, uma "reprodução ideal do movimento real do objeto pelo sujeito que pesquisa” (NETTO, 2009, p. 673). O método não é um conjunto de procedimentos formais capazes de decodificar o objeto de estudo (se corretamente aplicado e manejado), mas sim um caminho que auxilia na reconstrução da "lógica da coisa", do objeto. Muito menos a história limita-se a 
uma sucessão linear e evolutiva de acontecimentos desconexos (ainda que não se possa dizer, em absoluto, que os complexos sociais se conectem entre si, naturalmente, uns com os outros). Há, entre eles, unidade, embora não exista identidade, bem como uma dose de casualidade que tempera as lutas sociais. Portanto, teoria não é construção, mas reconstrução do movimento do real, perseguição e expressão teórica de seu movimento (sempre relativa), revelando tensões contidas na dinâmica da realidade, vinculadas à produção e reprodução do ser, seu desenvolvimento, empenhada em desvelar geneticamente o real, suas particularidades na totalidade da vida social, repleta e rica em múltiplas mediações, ou seja, conexões explicativas extraídas da própria realidade.

Ainda que o ponto de partida seja sempre ontológico, a razão tem o papel fundamental de pôr em movimento essa reconstrução, forcejar o real na sua dureza, na sua imediaticidade inata, sem o qual é impossível desvelá-lo. A razão, portanto, não se explica por si mesma, não gira no cérebro "ilustre" do filósofo e dos "acadêmicos" munidos da "varinha mágica" do conhecimento, não funda o real, não possui a potência de explicar a realidade sem se debruçar sobre ela. $\mathrm{O}$ que se defende aqui não é a eliminação da razão e a afirmação absoluta da realidade que se revela por si só, mas a unidade diversa entre o pensar e o fazer, entre a razão crítica e o imediato e materialmente posto. A teoria, então, possui outro papel que não pode ser identificado como "aplicação". Esse processo é orientado por um método que não se reduz a esquemas aplicativos de um conjunto de técnicas, mas como um caminho que orienta e tece as bases para que a razão se debruce sobre o real para produzir teoria sobre ele. Tudo isso, por ser ontológico, está metido na trama histórica, sob o legado histórico em um determinado momento histórico, imerso em dada sociabilidade em movimento que oferece o "chão", a base material, por onde as individualidades tomam decisões, elaboram alternativas, exercem suas condições de sujeito histórico possível, certamente limitado, relativamente ativo, marcado pela ordem do capital, tecido por lutas sociais. Objetiva-se, assim, outra relação entre teoria, método e história, muito distante de esquemas lógicos abstratos que impõem ao real uma dinâmica abstrata que deturpa ao invés de revelar, camufla ao invés de desvelar.

\section{O ponto de vista ontológico e o Serviço Social}

Em relação ao Serviço Social caberia, aqui, uma questão: qual a utilidade do ponto de vista ontológico, ora tratado, para uma categoria profissional cuja inserção na divisão social do trabalho lhe reserva a gestão de múltiplas expressões daquilo que é genericamente caracterizado como questão social ${ }^{4}$ ? A resposta a essa questão, certamente complexa, rica em determinações, é certeira: embora exista uma contradição estrutural entre uma profissão, cuja gênese esteve fortemente atrelada ao conservadorismo nas condições da sociabilidade burguesa em sua fase monopólica, e uma teoria social, cuja teleologia situa-se "para além do capital", o debate entre elas é de fundamental importância. Trata-se de caminho necessário (embora não único) para descortinar o imediatamente posto, distinguir as demandas sensíveis impostas pelo mercado de trabalho como componentes de seu fazer profissional, capaz de mensurar o sentido de sua competência, dimensionar, sem exageros, o alcance de sua ação, questionar a utilidade de sua força de trabalho na gestão do pauperismo, na busca dos caminhos adotados para essa empreitada e a natureza dessa profissão na sociabilidade em curso. Mas quais são os contextos imediatamente enfrentados pelos assistentes sociais nesse campo contraditório? Deixemos, para isso, que os "usuários" atendidos pelo Serviço Social manifestem esse rico, complexo e aparentemente caótico cenário, conforme trechos reproduzidos abaixo de Silva ${ }^{5}$ (2010, p. 116-117):

Recebo o Bolsa Família e o Renda Cidadã, eu estou recebendo um atrasado do governo, que ele tá me pagando. Dá R \$ 106 para cada um, só que não dá né? Porque a gente tem luz, tem água, tem muita coisa pra pagar, como eu pago imposto daqui, né, então tem muita coisa pra pagar. Então eu recebo só isso, R\$130 de um e R \$ 126 do outro. [...] Ajuda, papel não dá dinheiro né? Eu vivo com o papel também, só que o dinheiro pra eu pagar essas contas não dá, porque é muito caro, então pra mim pôr comida, essas coisas, dentro de casa não dá. Agora que nós vamos mudar, nós vamos passar a pagar aluguel, eu arrumei uma casa de R \$ 300 , então o meu menino vai pagar o aluguel pra mim e nós vamos ficar só nas coisas de comer, assim que nós vamos fazer, pra inteirar, pra ajudar (Ana, usuária da assistência social).

É a minha única renda, eu tinha faxinas, agora a minha mão tá quebrada, está sendo a minha única renda. Esse Bolsa Família é a minha cesta básica por mês, e vou no mercado supro aquilo que está faltando da cesta básica, o leite de segunda, quarta e sexta, reponho uma caixinha de leite e economizo. Agora, como eu já falei pra ela que eu estou desempregada, ela sabe que eu estou desempregada, que ela vai fazer outra renda pra mim, porque ela tá vendo um serviço pra mim [...] mas eu não posso por causa da mão, tenho que operar a mão primeiro, estou esperando o hospital me chamar, o SUS (Rosa, usuária da assistência social). 
O ponto de vista ontológico exige um procedimento que não suprime, em absoluto, as demandas ora relatadas (expressões fenomênicas do real). Tais relatos devem ser tomados como manifestações fenomênicas, imediatas, não apenas subjetivas e pessoais, ainda que tal cenário careça de ações, decisões e requintes que perpassam a esfera do individual. Devem ser apanhadas, portanto, na sua historicidade, como ações datadas, com determinado "chão" sócio-histórico, dentro de um processo de intensa mercantilização das relações humano-sociais, mediada por regras sociais bem definidas, concretamente dadas, moldada em traços culturais particulares, contexto esse que enriquece e potencializa cenários que podem desembocar em dramas pessoais profundos, criar e alimentar mentes insanas, produzir indivíduos coisificados e desumanizados. São, portanto, indivíduos social e historicamente constituídos a partir dos princípios e valores (burgueses, ainda que rearranjados sob condições socioculturais específicas), que oferecem a base em que se constituem individualidades sociais, por onde são construídas alternativas que alimentam tais individualidades e suas respectivas subjetividades.

É importante que o assistente social considere isso como fundamental, ainda que uma análise desse gênero, sob a perspectiva da totalidade, não seja algo tecido facilmente, tão somente por uma iniciativa sustentada em decisões subjetivas. Exige estudo, formação cultural abrangente, espírito crítico, atitude de negação do imediatamente exposto, postura ético-política, exige a adoção de um marco teórico que lhe dê as melhores condições para essa empreitada. Exige "fincar os pés" no real, nas condições objetivas da profissão, reconhecendo seus limites e forcejando ao máximo suas possibilidades e potencialidades. Assim, não estamos diante de um procedimento desnecessário aos "da prática", "filosófico", restrito aos acadêmicos ilustres, aos que se dedicam à investigação teórica da vida humana, mas de algo imprescindível à práxis profissional, essencial para sua objetivação crítica, como ação prático-crítica, que modifica substancialmente o produto materializado como intervenção profissional, mesmo considerando o inevitável limite do alcance dessas ações profissionais na sociabilidade em curso. $\mathrm{O}$ acerto na análise do real certamente oferece melhores condições para uma intervenção mais profunda e propositiva nesse real.

Reafirmar uma direção social inspirada no ponto de vista ontológico no Serviço Social supõe algumas iniciativas importantes, cruciais na atualidade, já que as discussões da década de 1990 mostram-se, hoje, insuficientes, carentes de maior clareza no seu entendimento. $\mathrm{O}$ atual estágio de desenvolvimento do capitalismo e as transformações em curso têm exigido maior rigor, densidade e clareza na explicação de temas como liberdade, democracia, cidadania, direitos, Estado, trabalho socioeducativo, entre outros, tão caros à direção social construída, denominada Projeto Ético-Político Profissional, e ao Código de Ética do assistente social. Mais do que isso, são centrais para a explicação do real, para a reconstrução de sua dinâmica e, claro, para a atuação profissional cotidiana em tempos repletos de armadilhas sustentadas na "solidariedade cidadã" e na "rede inclusiva" que se propõem "novas" e "modernas", substitutas da "superada" luta de classes.

Em primeiro lugar, é preciso reafirmar a formação de intelectuais e a crítica às modernas expressões do profissional técnico-operativo, executor firme e "competente" do imediatamente instituído. O que se pretende, aqui, com a defesa da formação de intelectuais (que em nada se aproxima dos ilustres acadêmicos no sentido do isolamento universitário imaginado, poço da "sabedoria" do conhecimento exato, neutro e livre de julgamentos de valor - nem mesmo com a associação imediata com a noção de "intelectual orgânico" desenvolvida por Gramsci) é defender a formação generalista, pautada no ponto de vista da totalidade, da perseguição do real como "concretopensado" (MARX, 1989). Defender a formação de profissionais que pensam e fazem, que propõem a partir do imediatamente posto, mas mirando o mediato, o não imediatamente revelado (embora existente), a trama que explica processos sociais contraditórios de indivíduos sociais, inseridos em dada sociabilidade, traçada sob sua economia política, que oferece as regras gerais do jogo social por onde os indivíduos se formam e tomam suas decisões. Isso, evidentemente, deve ser pensado a partir de outro desafio ontologicamente dado: a mercantilização do ensino e as dificuldades, agora ainda mais acentuadas, com o ensino a distância e com os cursos presenciais que não imprimem uma formação à qualidade necessária para a apreensão dos fundamentos da profissão (BRAZ; RODRIGUES apud SILVA et al., 2013). Isto vem trazendo um agravamento do fosso teórico entre os profissionais, situação adensada pelo aligeiramento das formações, inclusive em nível de pós-graduação. É necessário reafirmar a defesa da graduação e da pós-graduação presencial e criar estratégias para uma formação pós-universitária ${ }^{6}$ que auxiliem os estudos, permitam que eles se mantenham em ebulição como estímulo a incursões futuras mais profundas e consistentes, instigando a massa crítica dentro e fora dos espaços institucionais. Como já destacou NETTO (1996, p. 126, grifos do autor),

[...] confrontam-se dois 'paradigmas' de profissional: o técnico bem adestrado que vai operar instrumentalmente sobre demandas do mercado de trabalho tal como elas se apresentam ou o intelectual que, com qualificação operativa, vai intervir sobre aquelas demandas a partir da sua compreensão teórico-crítica, identificando a significação, os limites e as alternativas da ação focalizada. 
Em segundo lugar, é preciso explicar o sentido exato da pluralidade, ou seja, a defesa do debate radical dos diferentes marcos teóricos presentes no Serviço Social, apropriador do ponto de vista divergente, sua argumentação, sua lógica. Isso, evidentemente, não para afirmar a relatividade da verdade, como verdades, não para harmonizar "olhares diferentes" sobre a realidade e chamar isso de conhecimento (no estreito caminho da "profundidade" eclética), mas para qualificar a discussão, demonstrar as fragilidades e os ganhos, fortalecer a crítica a partir das contradições daquilo que se critica, avaliar suas limitações reais, efetivas. Somente assim é possível qualificarse como intelectual, construir e manter hegemonia, direção social e cultural estratégica (GRAMSCI, 1989).

\section{É preciso reafirmar que em} nada interessa uma

\section{racionalidade instrumental ao}

Serviço Social, ou seja, uma

orientação centrada no puro

manejo de índices, dados e

instrumentos, no reformismo

conservador, no equilíbrio

dinâmico/sistêmico da ordem e

na gestão acrítica, dócil e

"solidária" do pauperismo.

Em terceiro lugar, é essencial reafirmar a crítica radical à endogenia, reeditada, na atualidade, no Serviço Social, sob outros patamares. É importante argumentar criticamente contra a afirmação de que o Serviço Social se explica por si só, por um movimento específico que desemboca na ciência isolada, pobre, que crê na legitimidade da profissão por meio de uma "teoria específica do Serviço Social" (um debate velhíssimo), na defesa de sua fatia, na "pluralidade interdisciplinar", nas pequenas explicações locais e pontuais. O caminho não endógeno, por sua vez, não nega as particularidades da profissão; ao contrário, afirma-as sob o a perspectiva da totalidade, inquieta-se no sentido de reconstruir mediações que diminuam o distanciamento entre as produções teóricas sistematizadas pelo Serviço Social e a massa de profissionais. Não será possível, todavia, mesmo afirmando essa direção, extirpar o sincretismo (NETTO, 1992), um dado ontológico no Serviço Social, embora seja absolutamente possível e necessária a crítica permanente ao ecletismo.

Em quarto lugar, todo esse processo é impensável sem a adoção do ponto de vista do trabalho e a defesa daqueles que vivem da venda da força de trabalho. Isto, evidentemente, não como um jargão vazio, mas como um vínculo de classe, como uma opção que orienta a ação profissional. Assim sendo, as lutas sociais, o aquecimento da luta de classes, a presença dos movimentos sociais, são combustíveis essenciais à formação da consciência de classe, cruciais para o enfrentamento dos dilemas vivenciados no âmbito da profissão. Aliás, diga-se de passagem, não é por acaso que o projeto ético-político profissional somente pôde ser desenhado e fortalecido na década de 1980, momento em que as lutas sociais daqueles que vendem a sua força de trabalho estavam aquecidas. No cenário atual, ainda que a resistência exista, a sua presença é mais frágil e diluída.

Em quinto e último lugar, é preciso retomar a militância negando o militantismo, na linha do que já foi pontuado até aqui. A práxis como relação de unidade-diversidade entre a teoria e a prática, como unidade de diferentes (impensáveis separadamente), essenciais à ação subversiva, como vida intelectual necessariamente engajada na militância dentro e fora da profissão, não abandona, jamais, o estudo e a ação permanentes, dentro e fora das universidades e da profissão. Isto ajuda a evitar exageros, ilusões, entregas suicidas e desnecessárias, como também age contra a paralisia, o isolamento, a ação puramente institucional e focal, evocando radicalidade permanente, firmeza diante de aspectos inegociáveis. Como indicou Marx (2005, p. 151),

[...] É certo que a arma da crítica não pode substituir a crítica das armas, que o poder material tem que ser derrubado pelo poder material, mas a teoria converte-se em força material quando penetra as massas. A teoria é capaz de se apossar das massas ao demonstrar-se ad hominem, e demonstra-se ad hominem logo que se torna radical. Ser radical é agarrar as coisas pela raiz. Mas, para o homem, a raiz é o próprio homem.

A essas dificuldades somam-se outras: as tensões decorrentes da orientação do projeto profissional no sentido de garantir a qualidade e o acesso a direitos sociais por parte da população demandatária das políticas sociais e a impossibilidade concreta de realizar isto em muitos espaços profissionais. Se o profissional não tem clareza dos limites da ação profissional, ele tende a reforçar comportamentos e ações, ora messiânicas, ora fatalistas (IAMAMOTO, 1994, 2007), ambas de pouca resolutividade política. As consequências desse dilema, associadas às condições concretas do exercício profissional e ao agravamento da questão social e de suas múltiplas refrações, têm provocado o adoecimento e o arrefecimento de muitos profissionais. 


\section{Apontamentos finais: qual direção social?}

As reflexões aqui indicadas remetem a uma questão de fundo, nevrálgica para o debate crítico do Serviço Social na atualidade: qual o sentido da afirmação do projeto ético-político profissional em curso? Ou seja, qual direção social deve orientar esse projeto para que possamos reafirmá-lo e enfrentar a crise que não mais se anuncia?

Ainda que esse movimento, em absoluto, esteja circunscrito à esfera profissional (já que se vincula a amplos e complexos processos em curso e à correlação de forças entre os projetos societários que disputam espaços), perseguir a dinâmica do real, estimular uma racionalidade ontológica no processo de reconstrução de conhecimentos e na formulação de alternativas reais que descortinem o mediato na sua historicidade (portanto, muito além do gerenciamento do que frequentemente é chamado de "fazer o possível"), são procedimentos essenciais. Nesse sentido, sem qualquer recaída idealista, tensionar na direção do "impossível" é um exercício necessário nos diferentes níveis e espaços da vida social, não deixando de reconhecer o alcance restrito, mas importante, das profissões, de suas demandas particulares.

É preciso reafirmar que em nada interessa uma racionalidade instrumental ao Serviço Social, ou seja, uma orientação centrada no puro manejo de índices, dados e instrumentos, no reformismo conservador, no equilíbrio dinâmico/sistêmico da ordem e na gestão acrítica, dócil e "solidária" do pauperismo. Isso não significa, em absoluto, que o assistente social não deva se apropriar criticamente de uma dimensão técnico-operativa, mas que ela, por si, serve, tão somente (quando muito) para operar o instituído, o imediatamente posto, a demanda oficial solicitada à profissão, a administração burguesa da pobreza. A razão ontológica aqui desenvolvida não descarta o manejo crítico do instrumental, mas o submete a uma racionalidade que persegue o movimento do real, reconstrói sua dinâmica (sempre relativamente), desnuda o imediatamente posto e explica processos como determinados complexos sociais. Em outras palavras, a racionalidade ontológica deve reproduzir crítica e mentalmente a vida real de seres sociais reais em dada historicidade, deve estar afinada com a subversão da ordem que desumaniza homens e mulheres, captura sua potencialidade crítica, aliena-estranha seu trabalho e reproduz esse processo na sua vida social por inteiro. Não se trata, claro, de uma tarefa de profissões, mas de uma referência que orienta ações, baliza a direção social profissional, enriquece seu diálogo crítico, endossa o acúmulo social de forças e tensiona os limites do reformismo conservador que atuam direta ou indiretamente na profissão. O manejo de instrumentos e técnicas, nessas condições, pode ser útil para obter dados, sistematizar informações, lidar imediatamente com a empiria, desde que submetida à razão ontológica do ser e não como uma racionalidade que constitua a formação profissional.

O Projeto Ético-Político Profissional do Serviço Social vive uma crise que, evidentemente, não pode ser explicada por ela mesma, circunscrita às suas fronteiras, pois se vincula ao atual estágio de acumulação do capital (à historicidade em curso). Ao contrário das(os) companheiras(os) que blindam o Projeto com a boa intenção de defendê-lo, ou daqueles/as profissionais que conscientemente o ignoram e ou se dizem "defensores/defensoras" dele com o objetivo de esvaziá-lo (e não são poucos os/as filiados/as a essa segunda opção, altamente nefasta), é preciso assumir e enfrentar essa crise com firmeza e responsabilidade. Reafirmar o atual projeto Ético-Político Profissional possui o exato sentido de radicalizar suas bases e seus princípios, como direção estratégica profissional vinculada a uma direção social, comprometida com o ponto de vista do trabalho dos que vivem da venda da força de trabalho na sua diversidade contemporânea, tendo a razão ontológica (aqui tratada) como inspiração que se desdobra na formação profissional, no ensino, na pesquisa e na extensão, na vida dentro e fora das universidades e do espaço profissional. E no vínculo direto com os movimentos sociais, partidos políticos e organizações comprometidos com a crítica à ordem burguesa madura, marcada pela hegemonia do capital financeiro. Isso precisa se objetivar ética, política, teórica e praticamente com as estratégias necessárias no campo particular da formação e da atuação profissional do assistente social. Caso contrário, o Serviço Social e seus profissionais estarão fadados à pura reprodução do imediatamente posto; e o pior: em defesa do "Projeto Ético-Político Profissional"!

\section{Referências}

ALMEIDA, A. A. Possibilidades e limites da teoria do Serviço Social. Rio de Janeiro: Francisco Alves, 1978.

Reflexões sobre a construção do Serviço Social a partir de uma abordagem de compreensão, ou seja, interpretação fenomenológica do estudo científico do Serviço Social. Teorização do Serviço Social - Documentos. Rio de Janeiro: Agir, p. 183-193, 1986

ANTUNES, R. Adeus ao trabalho? Ensaios sobre as metamorfoses e a centralidade do mundo do trabalho. São Paulo: Cortez, 1999. . Os sentidos do trabalho. Ensaio sobre a afirmação e a negação do trabalho. São Paulo: Boitempo, 2000.

BRAZ, M.; RODRIGUES, M. O ensino de Serviço Social na era neoliberal (1990-2010): avanços, retrocessos de enormes desafios. In: 
SILVA, J. F. S. et al. (Org.). Sociabilidade burguesa e Serviço Social. Rio de Janeiro: Lumen Juris, 2013. No prelo. CBCISS - Centro Brasileiro de Cooperação e Intercâmvio de Serviços sociais. Teorização do Serviço Social: documentos de Araxá, Teresópolis e Sumaré. Rio de Janeiro: Agir, 1986.

FERNANDES, F. A revolução burguesa no Brasil: ensaio de interpretação sociológica. Rio de Janeiro: Guanabara, 1987.

HARVEY, D. Condição pós-moderna. Tradução de Adail Ubirajara Sobral e Maria Stela Gonçalves. São Paulo: Loyola, 2003.

GRAMSCI, A. Maquiavel, a política e o Estado moderno. Tradução de Luiz Mário Gazzaneo. Rio de Janeiro: Civilização Brasileira, 1989.

IAMAMOTO, M. V. Renovação e conservadorismo no Serviço Social: ensaios críticos. São Paulo: Cortez/Celats, 1994.

. Serviço Social em tempo de capital fetiche: capital financeiro, trabalho e questão social. São Paulo: Cortez, 2007.

IAMAMOTO, M. V; CARVALHO, R. de. Relações sociais e Serviço Social no Brasil. Esboço de uma interpretação históricometodológica. São Paulo: Cortez, 1985.

LENINE, V. I. O imperialismo: fase superior do capitalismo. Tradução de Leila Prado. São Paulo: Centauro, 2008.

LUKÁCS, G. Introdução a uma estética marxista. Tradução de Carlos Nelson Coutinho. Rio de Janeiro: Civilização Brasileira, 1978. . Ontologia do ser social: os princípios ontológicos de Marx. Tradução de Carlos Nelson Coutinho. São Paulo: Ciências Humanas, 1979.

. Prolegômenos para uma ontologia do ser social. Tradução de Carlos Nelson Coutinho São Paulo: Boitempo Editorial, 2010.

LUXEMBURGO, R. Reforma ou revolução? Tradução de Lívio Xavier. São Paulo: Expressão Popular, 2007.

MARX, K. O capital: crítica da economia política. Tradução de Regis Barbosa e Flavio R. Kothe. São Paulo: Abril Cultural, 1983. (v. 1, 1. 1, t. 1).

1, t. 2).

O capital: crítica da economia política. Tradução de Regis Barbosa e Flavio R. Kothe. São Paulo: Abril Cultural, 1984. (v. 1, 1.

O método da economia política. In: FERNANDES, F. (Org.). K. Marx,F. Engels: História. Tradução de Florestan Fernandes et al. São Paulo: Ática, 1989. (Coleção Grandes Cientistas Sociais 36).

. Crítica da filosofia do direito de Hegel. Tradução de Rubens Enderle e Leonardo de Deus. São Paulo: Boitempo, 2005.

. A ideologia alemã. Tradução de Rubens Enderle, Nélio Schneider e Luciano Cavini Martorano. São Paulo: Boitempo, 2007.

NETTO, J. P. (Org.). Georg Lukács. São Paulo: Ática, 1981, p. 122-123. (Coleção Grandes Cientistas Sociais).

NETTO, J. P. Ditadura e Serviço Social: uma análise do Serviço Social no Brasil pós-64. São Paulo: Cortez, 1991. . Capitalismo monopolista e Serviço Social. São Paulo: Cortez, 1992.

. Transformações societárias e Serviço Social: notas para uma análise prospectiva da profissão no Brasil. Serviço Social \& Sociedade, n. 50, p. 87-132, abr. 1996.

. Introdução ao método na teoria social. Serviço Social: direitos sociais e competências profissionais. Brasília: Cfess/Abepss, p. 667-700, 2009

SANTOS, L. L. Textos de Serviço Social. São Paulo: Cortez, 1983.

SILVA, J. F. S. da. Serviço Social: resistência e emancipação? 2010. 210 f. Tese (Livre-Docência) - Faculdade de Ciências Humanas e Sociais, Unesp de Franca, 2010. No prelo.

\section{Notas}

1 Os documentos de Araxá, Teresópolis, Alto da Boa Vista e Sumaré (produzidos entre 1967 e a segunda metade dos anos 1970, CBCISS, 1986), os estudos de Ana Augusta de Almeida (1978, 1986) e de Leila Lima dos Santos (1983) são sintomáticos para essa constatação. Vale destacar, todavia, o caráter infinitamente mais denso contido no estudo organizado por Santos conhecido como Método BH. Sobre a continuidade deste debate nos anos 1990, consultar Netto (1996).

2 Marx (1983, p. 196), no volume 1 de O capital, já indicava essa tendência: “nadaé nesse sentido mais característico do que a designação dada aos trabalhadores que trabalham todo tempo, de full time". Sobre o capital produtor de juros (D - D'), consultar o livro III, volume primeiro, de $O$ capital, particularmente a seção V, entre os capítulos XXI e XXVIII.

3 A realização de um valor de uso por meio da troca, processo mediado pela única mercadoria que não se compra ou vende (o dinheiro como equivalente geral), objetiva-se por meio de uma relação misteriosa, fetichizada que, aparentemente e de imediato, como produto final acabado, elimina o processo responsável pela produção de tais mercadorias (MARX, 1983, p. 70).

4 Questão social impensável sem a "Lei geral da acumulação capitalista” (MARX, 1984, p. 187).

5 De acordo com as características e os objetivos da pesquisa, está registrado que foram observados os procedimentos éticos das Resoluções do Conselho Nacional de Saúden. 196, de 10 out. 1996en. 251, de 7 ago. 1997. Todos os entrevistados receberame assinaram carta de consentimento de entrevista e de uso de suas opiniões. Os nomes utilizados são fictícios para preservar suas privacidades.

6 O curso atualmente mantido pelo Cfess e pela Abepss, em parceria com a Universidade de Brasília, em que pese suas limitações e problemas, é prova dessa possibilidade. 
José Fernando Siqueira da Silva

jfernandoss@terra.com.br

Doutor em Serviço Social pela Pontifícia Universidade Católica de São Paulo (PUC-SP)

Professor do Departamento de Serviço Social da Universidade Estadual Paulista Júlio de Mesquita Filho (Unesp/Franca)

\section{Unesp/Franca}

Faculdade de História, Direito e Serviço Social

Av. Eufrásia Monteiro Petráglia, 900, sala 35

Jardim Dr. Antonio Petráglia

Franca - São Paulo - Brasil

CEP: 14409-160 